\title{
DESIGN CONSIDERATIONS OF A COMBINATION MACHINE FOR CHOPPING AND MILLING ARUNDO DONAX (PART I)
}

\author{
Badr, M. M. ${ }^{1}$
}

\author{
M. M. A.El-Sharabasy ${ }^{2}$
}

\begin{abstract}
The aim of present work was to carry out theoretical analysis to design to design a combination machine to be suitable for chopping and milling Arundo donax plants and then to use the design considerations afterward to manufacture and evaluate the performance of the combination machine to reach up the optimum operating parameters. The design considerations included estimation of the following parameters: number of knives on the cutter-head, cutter-head speed, feed rolls speed and Arundo donax density in the feeding throat. The design considerations were evaluated taking into consideration the following indicators: theoretical cut length, theoretical capacity and required total power; furthermore determination of cutter-head shaft diameter as well as hammer mill shaft diameter. The design results reveal that the highest values of theoretical cut length and theoretical capacity were $(29.14 \mathrm{~mm}$ and $756 \mathrm{~kg} / \mathrm{h})$ respectively, while the lowest values of chopping and milling units power were (9.54 and $20.17 \mathrm{~kW})$, respectively and the values of cutter-head shaft diameter and hammer mill shaft diameter were (50 and $60 \mathrm{~mm}$ ), respectively under the following conditions: number of knives on the cutter-head of 2 knife, cutter-head speed of maximum $1400 \mathrm{rpm}$ and Arundo donax density in the feeding throat of $6.18 \mathrm{~kg} / \mathrm{m}^{3}$ with adjusting feed rolls speed of $1.36 \mathrm{~m} / \mathrm{s}$.
\end{abstract}

\section{INTRODUCTION}

rundo donax (giant reed, giant cane) is one of the largest grass
species. A plant that grows in dense stands, it is found in many
subtropical and warm-temperate areas of the world. It is thought to be native to eastern Asia, but the precise extent of its native distribution is unknown. Arundo has been introduced around the world as an ornamental/crop species, for erosion control, and for the production of reeds (musical instruments, construction, paper and pulp). It has become invasive in many places throughout the world, primarily in riparian habitat.

\footnotetext{
${ }^{1}$ Lecturer of Agric. Eng., Fac. of Agric., Zagazig Univ., Egypt.

${ }^{2}$ Assist. Prof. of Agric. Eng., Fac. of Agric., Zagazig Univ., Egypt.
} 
Where Arundo invades, it often forms dense stands, resulting in a wide range of impacts to natural ecological systems as well as human created infrastructure (Lowe et al. 2000). Arundo donax is a tall, erect, perennial cane-or reed-like grass, 2 to 8 meters high. It is one of the largest of the herbaceous grasses. The fleshy, almost bulbous, creeping root stocks form compact masses from which arise tough, fibrous roots that penetrate deeply into the soil. The culms reach a diameter of 1 to $4 \mathrm{~cm}$ and commonly branch during the second year of growth. These culms are hollow, with walls 2 to 7 $\mathrm{mm}$ thick and divided by partitions at the nodes. The nodes vary in length from 12 to $30 \mathrm{~cm}$. The leaves are conspicuously two-ranked, 5 to $8 \mathrm{~cm}$ broad at the base and tapering to a fine point. The bases of the leaves are cordate and more or less hairy-tufted, persisting long after the blades have fallen (Hoshovsky, 2003). Giant reed is one of the most promising crop for energy production for the Mediterranean climate of Europe and Africa, where it has showed advantages as indigenous crop (already adapted to the environment), durable yields, and resistance to long drought period. Several field studies have highlighted the beneficial effect of giant reed crop on the environment due to its minimal soil tillage, fertilizer and pesticide. Furthermore it offers protection against soil erosion (Heaton 2004). Arundo donax is strong candidate for use as a renewable bio-fuel source because of its fast growth rate, ability to grow in different soil types and climatic conditions. $A$. donax will produce an average of three kilograms of biomass per square meter (25 Mg per acre) once established. The energy density of the biomass produced is $17 \mathrm{MJ} / \mathrm{kg}$ regardless of fertilizer usage (Angelini et al. 2005).

In USA, a great effort (money and time) has been spent in developing effective procedures for Arundo removal. Management techniques such as manual and mechanical removal and fire, implemented have proven suboptimal. Manual or mechanical removal often results in dispersal of plant propagules, including rhizome fragments and stem nodes. Root masses can be missed and/or left behind, removal of the biomass can spread the invasion, and equipment used for physical extraction can spread the plant through fragments being caught in the machinery. In addition to these downfalls, manual eradication and removal of biomass is expensive. The price tag for only the above ground biomass cutting (not including removal from the site) is $\$ 5000$ USD per acre (Bell 1993). The larger machines can be 
used to remove above ground vegetation and dig up underground rhizomes. Vegetation can be chopped or trimmed back with a tractor. This nonselective method works well in monotypic stands of undesirable plants where there are no native plants nearby. This is often done in preparation of removal of underground rhizomes or prior to chemical treatment (Forest $\boldsymbol{e t}$ al. 2003). Crushing of crop residues is on the increase with the global quest for sourcing of renewable energy through pre-processing of bio-masses. Physical and mechanical properties of biomasses species and varieties are very important when considering the energy requirements for particle size reduction of agricultural residues. Of the various types of grinding equipment available, hammer mills are the best known equipment used for the shredding/grinding, in which the material fragment are subjected to complex forces and then the resulted particles are used in the following operations from the pellet obtaining technology (Moiceanu et al. 2012). The performance and productivity of size reduction equipments for fibrous materials were analyzed and recommended the hammer mill which accepts the whole stalks without the need for manual chopping. Various size reduction equipments are available in the market based on the classification of the size reduction equipment. They added an extended layout of this classification and suggested hammer mill, knife mill and disc mill as the proper equipment for biomass pulverization. Due to high size reduction ratio, good control of particle size range with relatively good cubic shape of particles, hammer mills are wildly used for grinding of different materials are available. Knife mills (or choppers) work successfully for shredding forages under various crops and machine conditions (Hoque et al. 2007). So, such care had to be taken to design a combination machine to be suitable for chopping and milling the Arundo donax plant to minimize operational cost and improve product quality. Thus, the objectives of this research are to carry out theoretical analysis to design a chopping and milling units for crushing Arundo donax plant. Addition to, determine the suitable power source for operating the combination machine.

\section{MATERIALS AND METHOD}

The design considerations were conducted through the year of 2014 at Department of Agricultural Engineering, Faculty of Agriculture, Zagazig University to design a combination machine then to use the design 
considerations afterward to manufacture a machine for chopping and milling Arundo donax to reach to optimum operating efficiency.

\subsection{MATERIALS:}

\subsubsection{The used plant:}

Arundo donax (Giant reed) was used in this study.

\subsubsection{The designed combination machine:}

Theoretical analysis of a combination machine suitable for chopping and milling Arundo donax was carried out to determine optimum design parameters. It consists of the main following parts as shown in Fig. (1):

\section{A-Chopping unit:}

The chopping unit consists of the following parts: feed inlet, feeding rolls, chopping drum and outlet.

\section{B- Milling unit:}

The milling unit consists of the following parts: feed hopper, milling chamber, milling drum, cover and concave.

\section{C- Power transmission:}

The combination machine was powered by a small tractor type (KubotaM5400) with engine power of $42.65 \mathrm{~kW}$ (58hp) at rated speed of $3000 \mathrm{rpm}$. Also a flywheel was attached to the chopping shaft to stop the reduction of the rotating speed noticed whenever much stalk materials were added to the chopping chamber. Fig.(2).

\section{D- The main frame:}

The main frame of the combination machine for chopping and milling Arundo donax stalks will be made from iron steel sheet. It includes three hitching points to be drawn with a small tractor and take its rotating motion from (pto) using pulleys and V-Belts.

\subsection{METHOD:}

\subsubsection{Physical and engineering properties of Arundo donax plant:}

Physical and engineering properties of Arundo donax plant under study have to be considered to study their effect on the performance of the combination machine.

A random sample of about 100 stalks was taken to determine some physical properties such as: length of plant, diameter of stalk, stalk thickness, particles density and mass of 10 stalks; and some engineering properties such as: coefficient of friction and repose angle. 


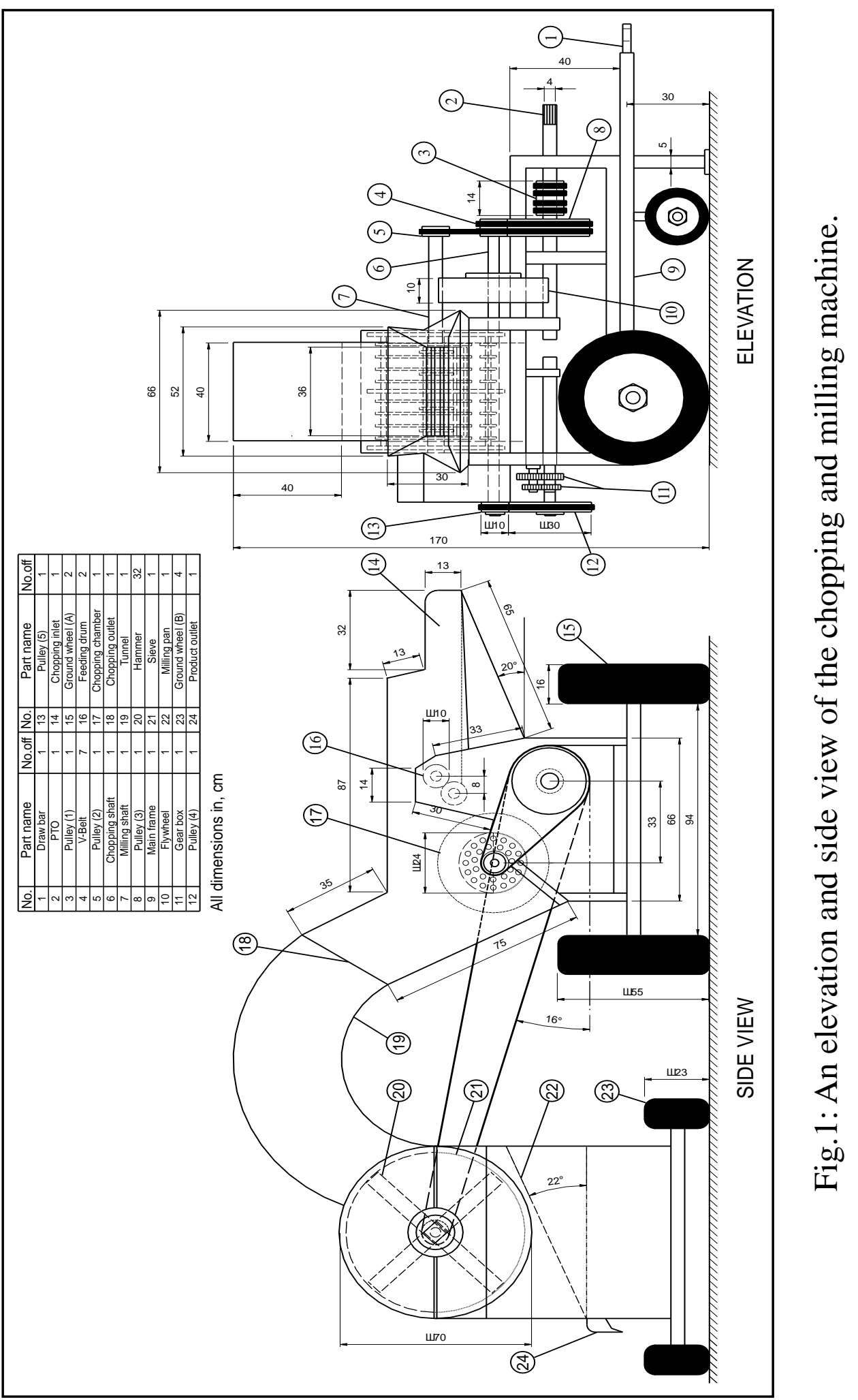




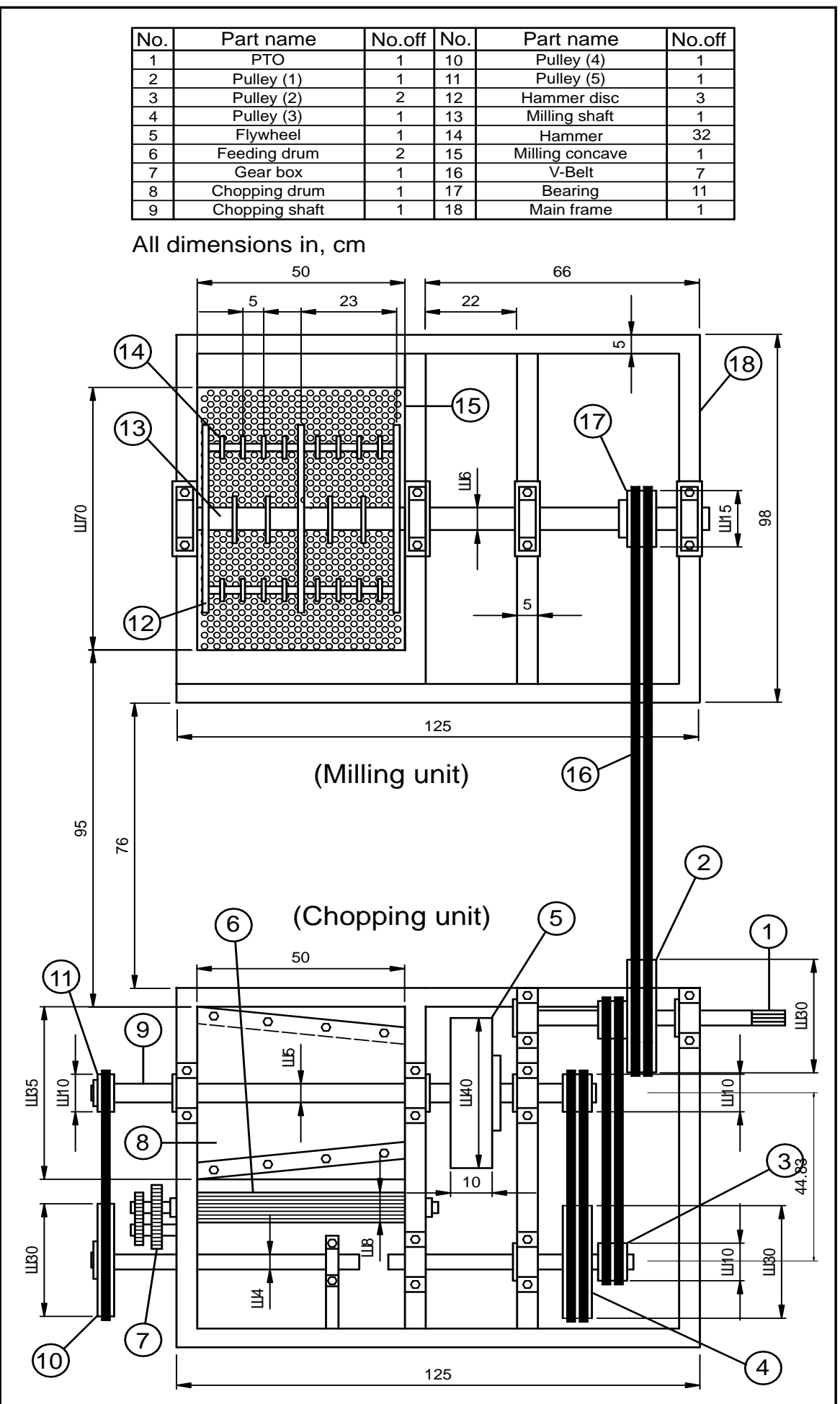

Fig.2: Schematic diagram showing power transmission from (pto) to chopping and milling units. 
Dimensions were measured using the digital vernire caliper of an accuracy of $0.01 \mathrm{~mm}$. The weights of samples were conducted using two electrical digital balances. Coefficient of friction of Arundo donax plant was measured using an inclined plane apparatus on surface of steel sheet metal. The measurements were repeated ten times for each sample. Some physical properties of the used Arundo donax plant were illustrated in Table (1).

Table 1: Some physical and engineering properties of Arundo donax.

\begin{tabular}{lc}
\hline \multicolumn{1}{c}{ Item } & Value \\
\hline Length of plant, $\mathrm{mm}$ & 2400 \\
Diameter of stalk, $\mathrm{mm}$ & 22.00 \\
Thickness of stalk, $\mathrm{mm}$ & 4.00 \\
Particles density, $\mathrm{kg} / \mathrm{m}^{3}$ & 160.65 \\
Coefficient of friction & 0.50 \\
Repose angle, degree & 30 \\
\hline
\end{tabular}

\subsubsection{Design considerations:}

Machinery designers and operators require more information concerning the required power for chopping Arundo stalks, which affects to a great extent the performance of chopping and milling machines. If this information is available, it is possible to design more developed machines and improve the performance of the existing machines. Chopping Arundo stalks can be performed using two cutting blades; the first blade is, responsible for cutting operation and the other is used as a counter-shear (i.e. to provide resistance against the cutting force).

The design of the cutting knife and the stalk type are considered the most affecting factors on performance of chopping machinery. There is a variation in the shear stress of Arundo staks due to the stalk diameter and the thickness. However, the Arundo stalks differ in their physical and mechanical properties. The moisture content level and the fiber and lignin content are considered as a limited factor to the stak physical and mechanical properties.

\subsubsection{Design of chopping and milling units:}

The dimensions of the chopping and milling units were selected according to the physical properties of the investigated plant such as; dimensions of feeding throat, shape of feeding rolls, shape of knives and diameter of concave openings that is executed efficiency optimum. While the remaining dimensions such as; hammer length, hammer width and hammer weight 
were designed according to the affecting force (shear force or impact force) at the end of the hammer to mill the chopped Arundo donax.

\section{- Calculation of the theoretical cut length:}

The length of cut is controlled by the peripheral speed of the feed rolls relative to the speed of the cutter-head. A smooth feed roll is placed near the shear bar to maintain the grip on the Arundo as close to the shear bar. In determining peripheral speeds of feed rolls, the pitch (effective) diameter is slightly less than the outside diameter. The theoretical length of cut can be calculated using the following equation (Srivastava et al. 1993):

$$
\mathrm{L}_{\mathrm{th}}=\frac{60000 \times \mathrm{v}_{\mathrm{f}}}{\lambda_{\mathrm{k}} \cdot \mathrm{n}_{\mathrm{c}}}
$$

Where: $L_{\text {th }}=$ theoretical length of cut, $\mathrm{mm}$.

$\mathrm{V}_{\mathrm{f}}=\mathrm{f} œ \mathrm{~d}$ velocity, $\mathrm{m} / \mathrm{s}=$ peripheral sped of fed rolls.

$\lambda_{k}=$ number of knives on the cutter-head.

$\mathrm{n}_{\mathrm{c}}=$ rotational sped of cutter-head, rev/min.

Some particles will be longer than the theoretical length when stems are not oriented parallel to the direction of feed. Others will be shorter than the theoretical length when the arrival of the ends of stems does not coincide with the arrival of a cutter-head knife. The actual length of cut is usually close to the theoretical length because the staks are oriented nearly perpendicular to the shear bar. For direct-cut Arundo, actual average lengths of cut are generally about $50 \%$ longer than the theoretical length. When Arundo stalks are being chopped, the average actual length of cut is much longer than the theoretical length due to the random stalks alignment. Large increases in theoretical length of cut are made by removing knives from cutter-head. Smaller changes in length of cut are made by adjusting the fœd velocity. The feed rolls will separate further to accommodate the reduced fed velocity until the maximum separation distance is reached; further reductions in fed velocity will then reduce the capacity of the machine.

\section{- Calculation of the theoretical capacity.}

The theoretical capacity of a precision-cut Arundo chopper can be cal culated using the following equation (Srivastava et al. 1993):

$$
\dot{\mathrm{m}}_{\mathrm{f}}=\frac{\rho_{\mathrm{a}} \mathrm{A}_{\mathrm{t}} \mathrm{L}_{\mathrm{th}} \lambda_{\mathrm{k}} \mathrm{n}_{\mathrm{c}}}{6 \times 10^{8}}
$$

Where: $\dot{\mathrm{m}}_{\mathrm{f}}=$ theoretical capacity or feed rate, $\mathrm{kg} / \mathrm{s}$. 
$\rho_{a}=$ density of Arundo in the throat, $\mathrm{kg} / \mathrm{m}^{3}$.

$\mathrm{A}_{\mathrm{t}}=$ throat area, $\mathrm{cm}^{2}$.

Before using equation (2) to calculate the maximum al lowable feed rate, the maximum throat area must be calculated. As follows:

$$
A_{t}=\text { cutter-head width } \times \text { throat height }
$$

After Arundo was chopped by the cutter-head, centrifugal force holds it against the housing as the cutter-head moves it toward the exit; the housing terminates at the bottom or rear of the cutter-head to allow the chopped material to escape. In a cut-and-throw machine, the cutter-head imparts sufficient energy to throw the chopped material to milling unit.

\section{- Determination of the total power for combination machine}

The required power of a combination machine is so large that chopping and milling capacities can be limited by available power. Power is consumed in feeding, conveying and compressing the material to be cut and mill. There after the final product can be packaged in sacks. The unexploited power losses in a combination machine include bearing friction, friction of the cut material on the cutter-head housing, impact between the hammers and materials, and pumping of air at the cutter-head and blower. Within the cutter-head and the mill hammers, energy is required for compressing shearing and impacting, for acceleration and air movement, and for overcoming friction at the housing. Material parameters such as shear strength, moisture content and friction coefficient, and machine parameters such as sharpness of the knife and length of cut will all affect the distribution of power in the combination machine.

\section{- Calculation of the required power for chopping unit:}

Chopping usually requires the greatest energy at the cutter-head, while friction generates the greatest energy requirement at the blower. The power requirement for chopping can be calculated using the following equation: (Srivastava et al. 1993):

$$
\mathrm{P}_{\mathrm{c}}=\frac{1000 \mathrm{C}_{\mathrm{f}} \mathrm{F}_{\mathrm{smax}} \dot{\mathrm{m}}_{\mathrm{f}}}{\rho_{\mathrm{a}} \mathrm{L}_{\mathrm{th}}}
$$

Where: $\mathrm{P}_{\mathrm{c}}=$ chopping power, $\mathrm{kW}$

$\mathrm{C}_{\mathrm{f}}=$ ratio of average to maximum specific cutting force.

$F_{\text {smax }}=$ maximum specific cutting force, $\mathrm{N} / \mathrm{mm}$ of counter shear length.

$\dot{\mathrm{m}}_{\mathrm{f}}=$ fed rate, $\mathrm{kg} / \mathrm{s}$. 
$\rho_{a}=$ density of material in the throat, $\mathrm{kg} / \mathrm{m}^{3}$.

$\mathrm{L}_{\mathrm{th}}=$ theoretical length of cut, $\mathrm{mm}$.

Thus, as with straight cutting, $\mathrm{C}_{\mathrm{f}}$ is about equal to 0.64 for typical oblique cutting. Chopping power varies with fed rate and length of cut; the specific cutting energy provides a better index for comparing machines of differing design. Specific cutting energy is defined as follows:

$$
\mathrm{E}_{\mathrm{sc}}=\frac{1000 \mathrm{C}_{\mathrm{f}} \mathrm{F}_{\text {smax }}}{\rho_{\mathrm{a}}}
$$

Where: $E_{s c}=$ specific cutting energy, J.m/kg.

By measuring power consumption while changing feed velocity and removing knives to change the theoretical length of cut. Once a value of $E_{s c}$ is known, the following equation can be used to calculate specific cutting energy:

$$
\mathrm{E}_{\mathrm{sc}}=\frac{\mathrm{P}_{\mathrm{c}} \mathrm{L}_{\mathrm{th}}}{\dot{\mathrm{m}}_{\mathrm{f}}}
$$

Notice from equation (4) that $E_{s c}$ is proportional to the maximum specific cutting force. Thus, maintaining sharp knives and shear bar/knife clearance is very important to reduce the power requirement for chopping Arundo. Power to overcome friction between the cut stalks and the cutter-head or blower housing can be calculated by using the following equation:

$$
\mathrm{P}_{\mathrm{fc}}=\frac{\beta \mu \dot{\mathrm{m}}_{\mathrm{f}} \mathrm{V}_{\mathrm{pc}}^{2}}{1000}
$$

Where: $P_{f c}=$ power absorbed by rubbing friction, $k W$.

$\beta=$ average arc of housing by chopped material, radians.

$\mu=$ coefficient of friction betwen Arundo and sted housing.

$\dot{\mathrm{m}}_{\mathrm{f}}=$ fed rate, $\mathrm{kg} / \mathrm{s}$.

$\mathrm{v}_{\mathrm{pc}}=$ peripheral velocity of cutter-head or blower, $\mathrm{m} / \mathrm{s}$.

Required power to accelerate the chopped material at the blower is derived by assuming that the Arundo leaves the blades at about the peripheral speed of the blades:

$$
\mathrm{P}_{\mathrm{ac}}=\frac{\dot{\mathrm{m}}_{\mathrm{f}} \mathrm{V}_{\mathrm{pc}}^{2}}{2000}
$$

Where: $\mathrm{P}_{\mathrm{ac}}=$ power to accelerate the chopped material, $\mathrm{kW}$. 
Both the cutter-head and the blower move air, al though the latter at a greater rate. According to well-established fan laws, fan power varies with the cube of the peripheral speed; the following equation was derived for the approximate air power:

$$
P_{\text {air }}=\frac{V_{p c}^{3}}{16600}
$$

Where: $P_{a i r}=$ power to move air, $\mathrm{kW}$.

By combining equations 4, 7, 8 and 9 (chopping power, power absorbed by rubbing friction, power to accelerate the chopped material and power to move air), the following equation can be used to calculate the chopping unit power:

$$
\mathrm{P}_{\mathrm{co}}=\mathrm{P}_{\mathrm{c}}+\mathrm{P}_{\mathrm{fc}}+\mathrm{P}_{\mathrm{ac}}+\mathrm{P}_{\mathrm{air}}
$$

\section{- Calculation of the required power for milling unit:}

Milling usually requires the greatest power at the hammer mill, while friction or accelerate the milled material generates the lowest energy requirement at the concave. When the maximum shear force of the investigated equal to the kinetic force at the end of hammer, kinetic force of hammer equal $1108 \mathrm{~N}$, the following equation can be used to be calculated or assumed for some parameters (Srivastava et al. 1993):

$$
\mathrm{F}_{\mathrm{s}}=\frac{\mathrm{m} \mathrm{v^{2 }}}{2 \mathrm{r}_{\mathrm{h}}}
$$

Where: $F_{s}=$ maximum shear force on stalks = kinetic force of hammer, $N$.

$\mathrm{m}=$ mass of hammer, $\mathrm{kg}$.

$\mathrm{v}=$ peripheral velocity of hammer mill, $\mathrm{m} / \mathrm{s}$.

$\mathrm{r}_{\mathrm{h}}=$ radius of hammer, $\mathrm{m}$.

Therefore, the required milling power can be calculated using the following equation:

$$
\mathrm{P}_{\mathrm{m}}=\mathrm{F}_{\mathrm{s}} \omega \mathrm{r}_{\mathrm{s}}
$$

Where: $P_{m}=$ milling power, $\mathrm{kW}$.

$\omega=$ Angular velocity of hammer shaft, $\mathrm{rad} / \mathrm{s}$

$\mathrm{r}_{\mathrm{s}}=$ radius of hammer, $\mathrm{m}$.

$$
\omega=\frac{2 \pi \times \mathrm{N}}{60}
$$

Where: $\mathrm{N}=$ rotation speed of hammer shaft, rpm. 
Power to overcome friction betwen the milling materials and housing of the milling hammers can be cal culated by using the following equation:

$$
\mathrm{P}_{\mathrm{fm}}=\frac{\beta \mu \dot{\mathrm{m}}_{\mathrm{f}} \mathrm{V}_{\mathrm{pm}}^{2}}{1000}
$$

Where: $P_{\mathrm{fm}}=$ power absorbed by rubbing friction, $\mathrm{kW}$.

$\beta=$ average arc of housing by milled material, radians.

$\mu=$ coefficient of friction betwen Arundo and sted housing.

$\dot{\mathrm{m}}_{\mathrm{f}}=$ fed rate, $\mathrm{kg} / \mathrm{s}$.

$\mathrm{v}_{\mathrm{pm}}=$ peripheral velocity of milling hammers, $\mathrm{m} / \mathrm{s}$.

Required power to accelerate the milled material at milling hammers can be calculated by using the following equation:

$$
\mathrm{P}_{\mathrm{am}}=\frac{\dot{\mathrm{m}}_{\mathrm{f}} \mathrm{V}_{\mathrm{pm}}^{2}}{2000}
$$

Where: $P_{a m}=$ power to accelerate the milled materia, $\mathrm{kW}$.

By combining equations 12, 14 and 15 (milling power, power absorbed by rubbing friction and power to accelerate the milled material), the following equation can be used to cal culate the milling unit power:

$$
\mathrm{P}_{\mathrm{mo}}=\mathrm{P}_{\mathrm{m}}+\mathrm{P}_{\mathrm{fm}}+\mathrm{P}_{\mathrm{am}}
$$

By combining equations 10 and 16 , an equation for the total consumption power, (chopping unit power and milling unit power) the total power of a combination machine; the following equation can be used to calculate the required total power:

$$
\mathrm{P}_{\mathrm{t}}=\mathrm{P}_{\mathrm{co}}+\mathrm{P}_{\mathrm{mo}}
$$

\section{Design of machine shafts:}

It is a great importance to design both cutter-head shaft and hammer mill shaft so as to save them from over loads and high stresses. Both shafts are subjected to combine torsion and bending stresses. So, they are calculated on the combined stress. The diameters of both shafts can be calculated according to the maximum shear stress theory as following (Khurmi and Gupta, 2005):

$$
\begin{array}{ll}
Z_{\max }=\frac{1}{2} \sqrt{\delta^{2}+Z^{2}} & Z_{\text {max }}=\frac{1}{2} \sqrt{\left(\frac{32 M}{\pi d^{3}}\right)^{2}+4\left(\frac{16 T}{\pi d^{3}}\right)^{2}} \\
Z_{\max }=\frac{16}{\pi d^{3}} \sqrt{M^{2}+T^{2}} & Z_{\text {max }}=\frac{16}{\pi d^{3}} \sqrt{K_{m}{ }^{2} M^{2}+K_{t}{ }^{2} T^{2}}
\end{array}
$$


Where:

$Z_{\text {max }}=$ Maximum shear stress, $Z_{\max }=500 \mathrm{~kg} / \mathrm{cm}^{2}$

$\delta=$ Bending stress, $\mathrm{kg} / \mathrm{cm}^{2} \quad Z=$ Torsion stress, $\mathrm{kg} / \mathrm{cm}^{2}$

$T=$ Maximum torque, $\mathrm{kg} . \mathrm{cm} \quad d=$ Diameter of cutter-head, $\mathrm{cm}$

$M=$ Maximum bending moment, $\mathrm{kg} . \mathrm{cm}$

$K_{m}=$ Shock factor for bending, $K_{m}=2.0$

$K_{t}=$ Shock factor for tension, $K_{t}=1.5$

- The theoretical analysis and design considerations were carried out as a function of changing in the following parameters:

- Four different number of knife on the cutter-head of (1, 2, 3 and 4 knife).

- Four different cutter-head speeds of (1000, 1200, 1300, and $1400 \mathrm{rpm})$ or $(18.32,21.98,23.81$ and $25.64 \mathrm{~m} / \mathrm{s})$.

- Four different feed rolls speed $(0.89,1.05,1.23$, and $1.36 \mathrm{~m} / \mathrm{s})$.

- Four different Arundo donax densities in the feding throat (5.00, 5.40, 5.74 , and $6.18 \mathrm{~kg} / \mathrm{m}^{3}$ ).

The design considerations were studied taking into consideration the following indicators: theoretical cut length, theoretical capacity and required total power; furthermore determine both cutter-head shaft and hammer mill shaft diameters.

\section{RESULTS AND DISCUSSION}

The obtained results will be discussed under the following items:

\subsection{Influence of cutter-head speed and number of cutter-head knives on theoretical cut length:}

The effect of cutter-head speed on theoretical cut length is shown in Fig.3. Results show that increasing cutter-head speed from 1000 to $1400 \mathrm{rpm}$ measured at different feed rolls speed of about $0.89,1.05,1.23$ and $1.36 \mathrm{~m} / \mathrm{s}$, decreased theoretical cut length from 26.70 to 19.07, from 31.50 to 22.50, from 36.90 to 26.36 and from 40.80 to $29.14 \mathrm{~mm}$, respectively at constant number of knives on the cutter-head of 2 knives.

The effect of number of the cutter-head knives on theoretical cut length is given in Fig.3. Results show that increasing number of the cutter-head knives from 1 to 4 knives measured at the same feed rolls speed, decreased theoretical cut length from 38.14 to 9.54 , from 45.00 to 11.25 , from 52.71 to 13.18 and from 58.29 to $14.57 \mathrm{~mm}$, respectively at constant cutter-head speed of $1400 \mathrm{rpm}$. 

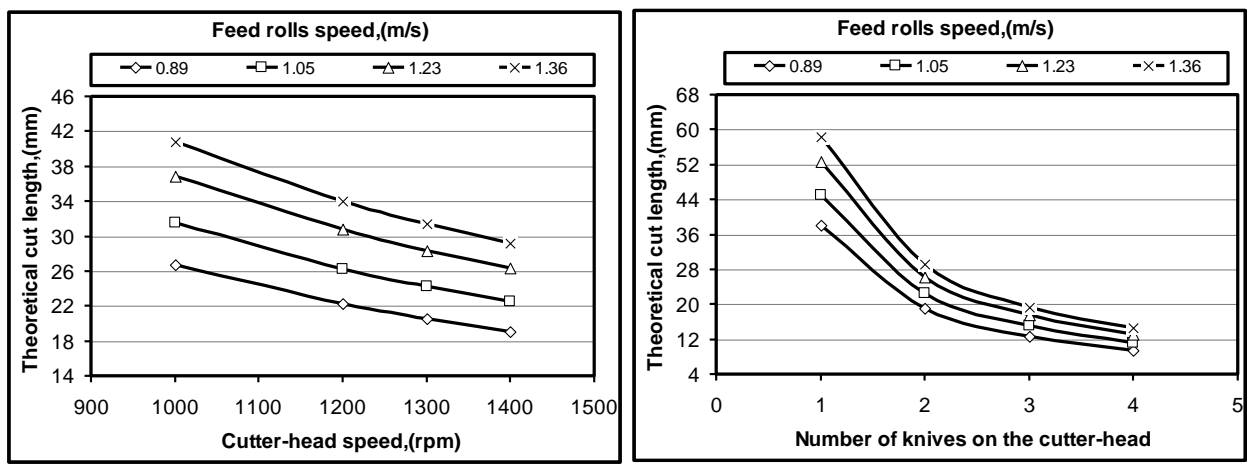

Fig.3. Effect of cutter-head speed and number of cutter-head knives on theoretical cut length.

The theoretical cut length decreased by increasing cutter-head speed due to the increase in cutting force and friction of the Arundo donax stalks on the cutter-head. And also, the theoretical cut length decreased by increasing number of the cutter-head knives due to the increase in number of strikes on Arundo donax stalks per time unit.

\subsection{Influence of cutter-head speed and number of cutter-head knives on theoretical capacity:}

The effect of cutter-head speed on theoretical capacity is shown in Fig.4. Results show that increasing cutter-head speed from 1000 to $1400 \mathrm{rpm}$ measured at different Arundo density in the throat of about 5.00, 5.40, 5.74 and $6.18 \mathrm{~kg} / \mathrm{m}^{3}$, increased theoretical capacity from 437 to 612 , from 472 to 660 , from 501 to 702 and from 540 to $756 \mathrm{~kg} / \mathrm{h}$, respectively at constant number of knives on the cutter-head of 2 knives.
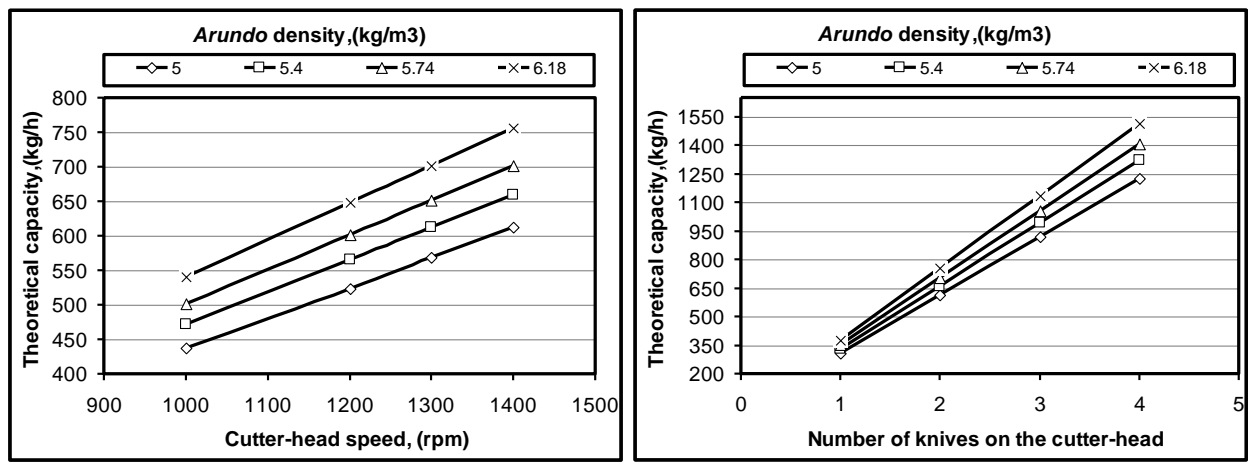

Fig.4. Effect of cutter-head speed and number of cutter-head knives on theoretical capacity.

The effect of number of the cutter-head knives on theoretical capacity is given in Fig.4. Results show that increasing number of the cutter-head knives from 1 to 4 knives measured at the same Arundo density in the throat, 
increased theoretical capacity from 306 to 1223 , from 330 to 1321 , from 351 to 1404 and from 378 to $1512 \mathrm{~kg} / \mathrm{h}$, respectively at constant cutter-head speed of $1400 \mathrm{rpm}$. The theoretical capacity increased by increasing cutter-head speed on account of the increase of chopped Arundo donax flow through the feeding opening at the same time unit. With respect to the theoretical capacity increased by increasing number of the cutter-head knives due to the increase in number of cutter-head action at the same time unit.

\subsection{Influence of feed rate and theoretical cut length on required total}

\section{power:}

The effect of feed rate on the required total power is shown in Fig.5. Results show that increasing feed rate from 612 to $756 \mathrm{~kg} / \mathrm{h}$ measured at different Arundo density in the throat of about 5.00, 5.40, 5.74 and $6.18 \mathrm{~kg} / \mathrm{m}^{3}$, increased required total power from 29.72 to 31.67 , from 29.10 to 30.91 , from 28.65 to 30.35 and from 28.13 to $29.71 \mathrm{~kW}$, respectively at constant theoretical cut length of $26.36 \mathrm{~mm}$. The effect of theoretical cut length on the required total power is shown in Fig.5. Results show that increasing theoretical cut length from 19.07 to $29.14 \mathrm{~kg} / \mathrm{h}$ measured at the same Arundo density in the throat decreased required total power from 35.38 to 30.56 , from 34.35 to 29.89 , from 33.59 to 29.38 and from 32.72 to $28.82 \mathrm{~kW}$, respectively at constant feed rate of $756 \mathrm{~kg} / \mathrm{h}$. The required total power increased by increasing feed rate on account of the increase of the excessive load of materials on the machine devices which consumed more power. With respect to the required total power decreased by increasing theoretical cut length due to the decrease of the loaded materials on the machine devices which consumed less power.
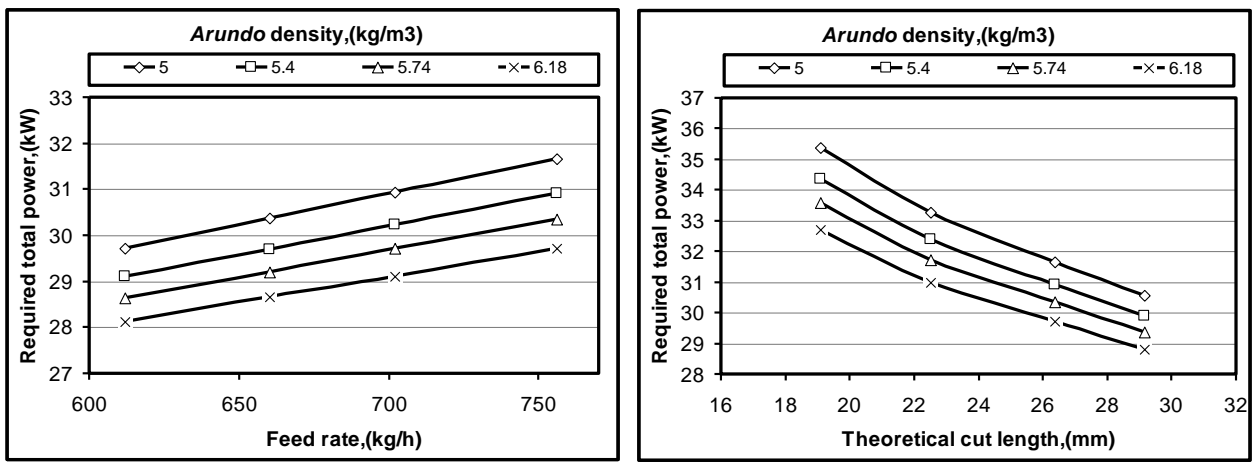

Fig.5. Effect of feed rate and theoretical cut length on the required total power. 


\subsection{Design the cutter-head shaft taking working power of $10 \mathrm{~kW}$.}

\section{a) Vertical loads subjecting on the cutter-head shaft:}

- Torque transmitted by the cutter-head shaft (T) can be calculated as follows: (Khurmi and Gupta 2005).

$$
T=\frac{P o \times 60}{2 \pi N}=\frac{10.5 \times 10^{3} \times 60}{2 \times 3.14 \times 1400}=71.65 \mathrm{~N} . \mathrm{m} \cong 72 \times 10^{3} \mathrm{~N} . \mathrm{mm}
$$

Assume the torque at pulley-3 (Point C) and pulley-4 (Point D) is in same value; therefore the tangential force $\left(\mathrm{F}_{1}\right.$ and $\left.\mathrm{F}_{2}\right)$ will be as follows:

$$
F_{t} \text { at } C \text { and } D=\frac{T}{r}=\frac{72 \times 10^{3}}{53}=1360 \mathrm{~N}
$$

\section{$\downarrow$ Determination of $F_{1}$ and $F_{2}$ :}

$$
F_{1}=T_{1}+T_{2}
$$

Where: $F_{1}=$ Tension force on pulley-3 and pulley- $4, \mathrm{~N}$

$T_{1}=$ Tension on the tight side of belt, $\mathrm{N}$

$T_{2}=$ Tension on the slack side of belt, $\mathrm{N}$

$$
T_{m}=F_{\max } \times r
$$

Where: $T_{m}=$ Torque at pulley shaft, N.mm

$F_{\max }=$ Maximum tension force at cutter-head shaft, $\mathrm{N}$

$r=$ Radius of pulley- 3 and pulley- $4, \mathrm{~mm}$

$T_{m}=1360 \times 53=72 \times 10^{3} \mathrm{~N} . \mathrm{mm}$

$$
\begin{aligned}
T_{m}= & \left(T_{1}-T_{2}\right) \times r \quad \therefore\left(T_{1}-T_{2}\right)=1360 \\
& 2.3 \log \left(T_{1} / T_{2}\right)=\mu \phi \cos \alpha
\end{aligned}
$$

Where: $\mu=$ Coefficient of friction, 0.3

$\alpha=$ Groove angle of pulley- 3 and pulley- $4,\left(30^{\circ}-40^{\circ}\right)$

$\phi=$ Angle of contact, rad.

$$
\begin{aligned}
& \phi=(180-2 \alpha) \cdot \pi / 180=(180-2 \times 35) 3.14 / 180=1.92 \mathrm{rad} \\
& \because 2.3 \log \frac{T_{1}}{T_{2}}=0.3 \times 1.92 \times \cos 35 \quad \therefore 2.3 \log \frac{T_{1}}{T_{2}}=0.472 \\
& \therefore \frac{T_{1}}{T_{2}}=e^{0.472 \times 2.3} \quad \therefore \frac{T_{1}}{T_{2}}=2.96 \\
& \because\left(T_{1}-T_{2}\right)=1440 \quad \therefore 2.96 T_{2}-T_{2}=1440 \quad \therefore 1.96 T_{2}=1440
\end{aligned}
$$


So, $T_{2}=693.8 \approx 694 N$ and $T_{1}=2.96 \times 694=2054.24 \approx 2054 N$

Then $F_{1}=2748 \mathrm{~N}$ andalso $F_{2}=2748 \mathrm{~N}$

But each pulley transfer tension force at $16^{\circ}$ from horizontal. So, the vertical tension force acting on the pulleys ( 3 and 4 ) equal:

$$
T_{V}=T \cdot \sin 16^{\circ}=2748 \times 0.276=757.45 \cong 757 \mathrm{~N}
$$

- Vertical force acting on the chopping shaft due to its weight (Acting as uniformly distributed load): $F_{l V}=W_{l}=100 \mathrm{~N} / \mathrm{m}$

- Vertical force acting on the pulley-3 due to its weight at (Point C):

$$
F_{2 V}=W_{2}=5 \mathrm{~N}
$$

- Vertical force acting on the pulley-4 due to its weight at (Point F):

$$
F_{3 V}=W_{3}=5 \mathrm{~N}
$$

- Vertical force acting on the flywheel due to its weight at (Point E):

$$
F_{4 V}=W_{4}=80 \mathrm{~N}
$$

b) Horizontal loads subjecting on the cutter-head shaft:

- Horizontal tension force acting on the pulleys ( 3 and 4) equal:

$$
T_{H}=T \cdot \cos 16^{\circ}=2748 \times 0.961=2641.55 \cong 2642 \mathrm{~N}
$$

- Horizontal force acting on the chopping shaft due to the weight of Arundo donax feed rate (Acting as uniformly distributed load):

$$
F_{1 H}=W_{4}=100 \mathrm{~N} / \mathrm{m}
$$

The vertical and horizontal loading diagram is shown in (Fig.6).

- The maximum bending moment for vertical and horizontal loadings could be obtained after calculating the reactions at the bearings A and B.

From the loading diagram in Fig.(6), the calculation vertical reactions were:

$$
\begin{array}{lll}
R_{A V}=460 \mathrm{~N} & \& & R_{B V}=1194 \mathrm{~N} \\
R_{A H}=1610 \mathrm{~N} & \& & R_{B H}=3724 \mathrm{~N}
\end{array}
$$

- The maximum bending moment for vertical loading being at (Point B) and equal:

$$
M_{B V}=31590 \mathrm{~N} . \mathrm{cm}
$$

- The maximum bending moment for horizontal loading being at (Point B) and equal:

$$
M_{B H}=105690 \mathrm{~N} . \mathrm{cm}
$$

- Resultant bending moment at (Point B) equal: (Khurmi and Gupta 2005).

$$
\begin{aligned}
& M_{R}=\sqrt{\left(M_{B V}\right)^{2}+\left(M_{B H}\right)^{2}}=\sqrt{(31590)^{2}+(105690)^{2}}=110310 \mathrm{~N} . \mathrm{cm} \\
& \therefore M_{R}=1103100 \mathrm{~N} . \mathrm{mm}
\end{aligned}
$$


FARM MACHINERY AND POWER

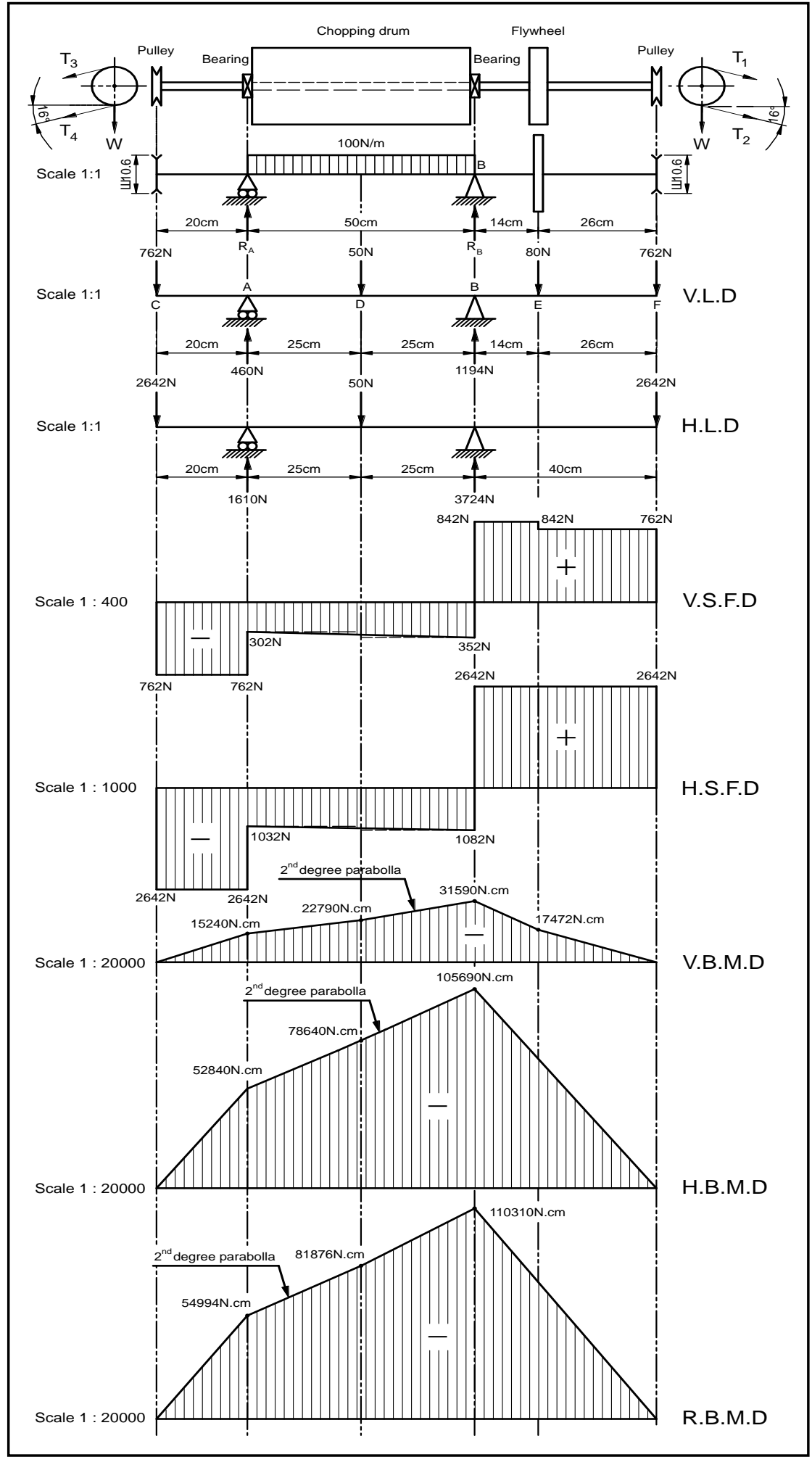

Fig.6: Vertical and horizontal diagrams of loads, shearing and moments for the designed cutter-head shaft.

Misr J. Ag. Eng., April 2014 
- Maximum shear theory at (Point B) equal:

$$
\begin{gathered}
Z_{\max }=\frac{16}{\pi d^{3}} \sqrt{K_{m}{ }^{2} M^{2}+K_{t}{ }^{2} T^{2}} \\
500=\frac{16}{\pi \cdot d^{3}} \cdot \sqrt{2^{2}(1103100)^{2}+1.5^{2}\left(72 \times 10^{3}\right)^{2}}=\frac{16}{3.14 d^{3}} \times \frac{2208842}{9.81 \times 10} \\
\therefore d^{3}=114.81 \quad \therefore d=4.86 \mathrm{~cm}=48.59 \mathrm{~mm} \\
500=\frac{16}{\pi \cdot d^{3}} \cdot \sqrt{2^{2}(1103100)^{2}+1.5^{2}\left(72 \times 10^{3}\right)^{2}}=\frac{16}{3.14 d^{3}} \times \frac{2208842}{9.81 \times 10} \\
\therefore d^{3}=114.81 \quad \therefore d=4.86 \mathrm{~cm}=48.59 \mathrm{~mm}
\end{gathered}
$$

So, the diameter of the cutter-head shaft was designed to be $\mathbf{5 0} \mathbf{~ m m}$.

\subsection{Design the hammer mill shaft taking working power of $21 \mathrm{~kW}$.}

a) Vertical loads subjecting on the hammer mill shaft:

- Torque transmitted by the hammer mill shaft (T) can be calculated as follows: (Khurmi and Gupta 2005).

$$
T=\frac{P o \times 60}{2 \pi N}=\frac{21 \times 10^{3} \times 60}{2 \times 3.14 \times 2500}=80.25 \mathrm{~N} . \mathrm{m} \cong 80 \times 10^{3} \mathrm{~N} . \mathrm{mm}
$$

Assume the torque at pulley- 2 (Point $C)=\left(80 \times 10^{3}\right)$, therefore the tangential force will be as follows:

$$
\begin{gathered}
F_{t} \text { at } C=\frac{T}{r}=\frac{80 \times 10^{3}}{50}=1600 \mathrm{~N} \\
F_{1}=T_{1}+T_{2}
\end{gathered}
$$

Where: $F_{l}=$ Tension force on pulley-2, N

$T_{1}=$ Tension on the tight side of belt, $\mathrm{N}$

$T_{2}=$ Tension on the slack side of belt, $\mathrm{N}$

$$
\begin{gathered}
T_{m}=\left(T_{1}-T_{2}\right) \times r \quad \therefore \quad\left(T_{1}-T_{2}\right)=1600 \\
80 \times 10^{3}=\left(T_{1}-T_{2}\right) \times 50 \quad \therefore\left(T_{1}-T_{2}\right)=1600 \\
2.3 \log \left(T_{1} / T_{2}\right)=\mu \phi \cos \alpha \\
\phi=(180-2 \alpha) . \pi / 180=(180-2 \times 35) 3.14 / 180=1.92 \mathrm{rad} \\
\because 2.3 \log \frac{T_{1}}{T_{2}}=0.3 \times 1.92 \times \cos 35 \quad \therefore 2.3 \log \frac{T_{1}}{T_{2}}=0.472 \\
\therefore \frac{T_{1}}{T_{2}}=e^{0.472 \times 2.3} \quad \therefore \quad \frac{T_{1}}{T_{2}}=2.96
\end{gathered}
$$

$$
\begin{aligned}
& \because\left(T_{1}-T_{2}\right)=1600 \quad \therefore 2.96 T_{2}-T_{2}=1600 \quad \therefore 1.96 T_{2}=1600 \\
& \text { So, } T_{2}=816.32 \approx 816 N \text { and } T_{1}=2.96 \times 816=2415.36 \approx 2415 \mathrm{~N}
\end{aligned}
$$

$$
\text { Then } F_{1}=3231 \mathrm{~N}
$$


But the pulley transfer tension force at $16^{\circ}$ from horizontal.

So, the vertical tension force acting on the pulleys- 2 equal:

$$
T_{V}=T \cdot \sin 16^{\circ}=3231 \times 0.276=892 \mathrm{~N}
$$

- Vertical force acting on the hammer mill shaft due to its weight and chopped Arundo donax (Acting as uniformly distributed load):

$$
F_{1 V}=W_{1}=524 \mathrm{~N} / \mathrm{m}
$$

- Vertical force acting on the pulley-2 due to its weight at (Point C):

$$
F_{2 V}=5 \mathrm{~N}
$$

\section{b) Horizontal loads subjecting on the hammer mill shaft:}

- Horizontal tension force acting on the pulleys- 2 equal:

$$
T_{H}=T \cdot \cos 16^{\circ}=3231 \times 0.961=3105 \mathrm{~N}
$$

The vertical and horizontal loading diagram is shown in (Fig.7).

- The maximum bending moment for vertical and horizontal loadings could be obtained after calculating the reactions at the bearings A and B. From the loading diagram in Fig.(7), the calculation vertical reactions were:

$$
\begin{array}{lll}
R_{A V}=838 N & \& & R_{B V}=1997 N \\
R_{A H}=3353 N & \& & R_{B H}=6458 N
\end{array}
$$

- The maximum bending moment for vertical loading being at (Point B) and equal:

$$
M_{B V}=48450 \text { N.cm }
$$

- The maximum bending moment for horizontal loading being at (Point B) and equal:

$$
M_{B H}=167650 \mathrm{~N} . \mathrm{cm}
$$

- The resultant bending moment at (Point B) equal:

$$
\begin{aligned}
& M_{R}=\sqrt{\left(M_{B V}\right)^{2}+\left(M_{B H}\right)^{2}}=\sqrt{(48450)^{2}+(167650)^{2}}=172590 \mathrm{~N} . \mathrm{cm} \\
& \therefore M_{R}=1725900 \mathrm{~N} . \mathrm{mm}
\end{aligned}
$$

- Resultant bending moment at (Point B) equal: (Khurmi and Gupta 2005).

$$
\begin{aligned}
& M_{R}=\sqrt{\left(M_{B V}\right)^{2}+\left(M_{B H}\right)^{2}}=\sqrt{(48450)^{2}+(167650)^{2}}=172590 \mathrm{~N} . \mathrm{cm} \\
& \therefore M_{R}=1725900 \mathrm{~N} . \mathrm{mm}
\end{aligned}
$$

- Maximum shear theory at (Point B) equal:

$$
\begin{aligned}
& 500=\frac{16}{\pi \cdot d^{3}} \cdot \sqrt{(1725900)^{2}+\left(80 \times 10^{3}\right)^{2}}=\frac{16}{3.14 d^{3}} \times \frac{1727753}{9.81 \times 10} \\
& \therefore d^{3}=179.48 \quad \therefore d=5.64 \mathrm{~cm}=56.4 \mathrm{~mm}
\end{aligned}
$$

So, the diameter of the cutter-head shaft was designed to be $\mathbf{6 0} \mathbf{~ m m}$. 


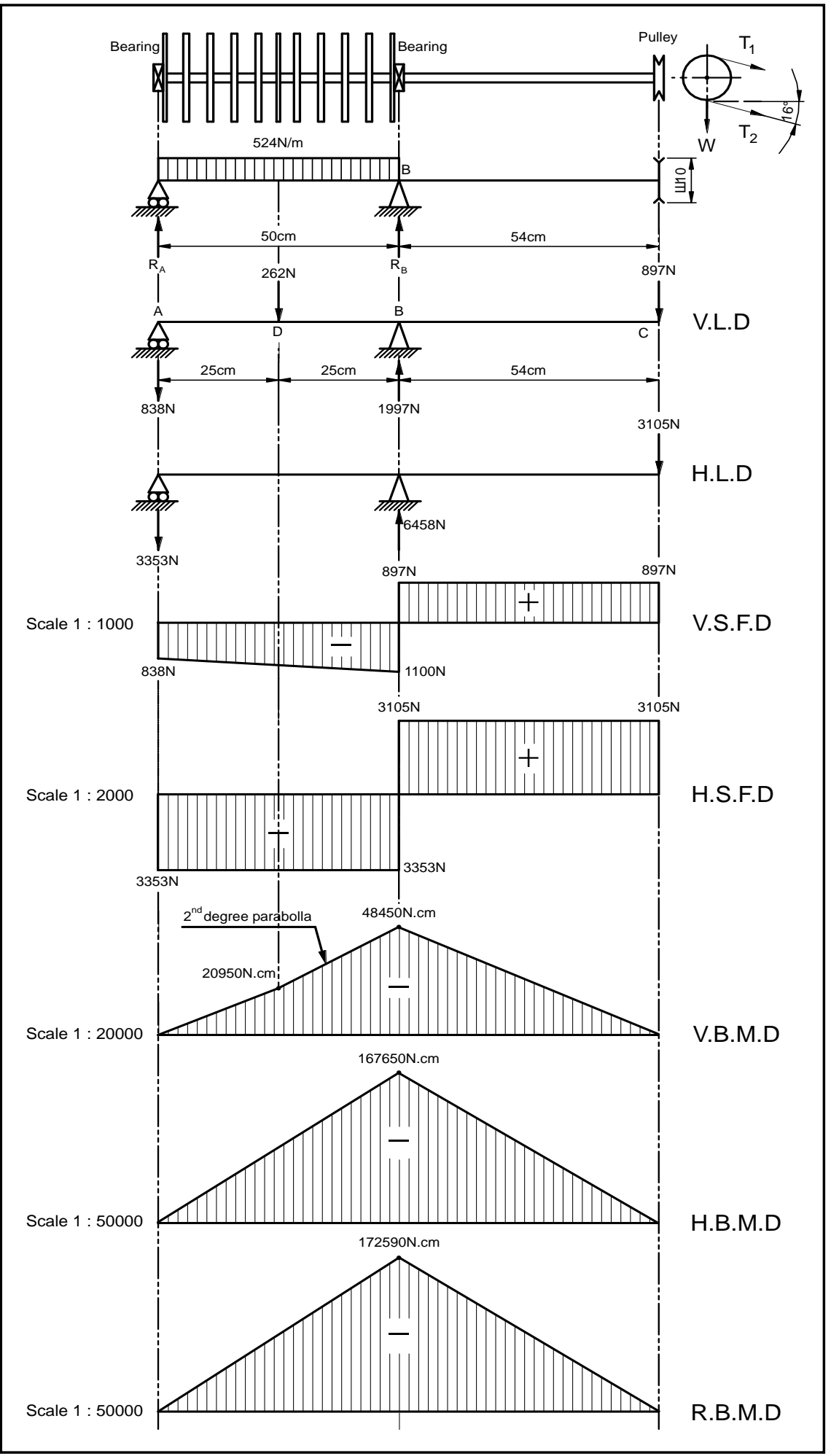

Fig.7: Vertical and horizontal diagrams of loads, shearing and moments for the designed hammer mill shaft. 


\section{CONCLUSION}

Design consideration of a machine for chopping and milling Arundo donax plants were carried out in Agricultural Engineering Department, Faculty of Agriculture, Zagazig University as they are necessary in manufacture process. The obtained design results reveal that the highest values of theoretical cut length, theoretical capacity were $29.14 \mathrm{~mm}$ and $756 \mathrm{~kg} / \mathrm{h}$, respectively, while the lowest values of chopping and milling unit's power were 9.54 and $20.17 \mathrm{~kW}$, respectively. The values of cutterhead shaft diameter and hammer mill shaft diameter were 50 and $60 \mathrm{~mm}$, respectively under the following conditions: number of knives on the cutter-head of 2 knives, cutter-head speed of about $1400 \mathrm{rpm}$ and Arundo donax density in the feeding throat of about $6.18 \mathrm{~kg} / \mathrm{m}^{3}$ with adjusting feed rolls speed on $1.36 \mathrm{~m} / \mathrm{s}$.

\section{REFERRENCES}

Angelini, L.G; L. Ceccarinia, and E. Bonarib (2005): European Journal of Agronomy, 22, 2005, pp 375-389

Bell, G. P. (1993): Prado Basin resource management plan for the control of Giant Reed (Arundo donax). The Nature Conservancy.

Forest, S; S. Kim and L. Loope (2003): United States Geological Survey-Biological Resources Division Haleakala Field Station, Maui, Hawai' I, January, 2003.

Heaton, E; T. Voigt and S. P. Long (2004): A quantitative review comparing the yields of two candidate $\mathrm{C} 4$ perennial biomass crops in relation to nitrogen, temperature and water. Biomass and Bioenergy. 27:21-30.

Hoque M; S. Sokhansanj, L. Naimi, X. Bi and J. Lim (2007): Review and analysis of performance and productivity of size reduction equipment for fibrous materials. ASABE paper no: 076164 St. Joseph, Mich., pp2-6.

Hoshovsky, Marc (2003): ELEMENT STEWARDSHIP ABSTRACT for Arundo donax (Giant Reed). THE NATURE CONSERVANCY. 1815 North Lynn Street, Arlington, Virginia 22209 (703) 8415300.

Khurmi, R. S. and J. K. Gupta (2005): A textbook of machine design. Eurasia Publishing House (Pvt) LTD. RAM Nagar, New Delhi. 110055. 
Lowe, S. J; M. Browne and S. Boudjelas (2000): 100 of the World's

Worst Invasive Alien Species, Published by the IUCN/SSC Invasive Species Specialist Group (ISSG), Auckland, New Zealand. http://www.issg.org/worst100_species.html.

Moiceanu, G; V. Gheorghe, G. Paraschiv, C. P. Ion and P. Maican (2012): Physical characteristics of miscanthus plant and power demand at grinding process. Engineering for Rural Development Jelgava 24, pp222.

Srivastava, A. K; C. E. Goering and R. P. Rohrback (1993): Engineering principles of agricultural machines. Transaction of ASAE Textbook. No 6. St. Joseph, MI, 1993.

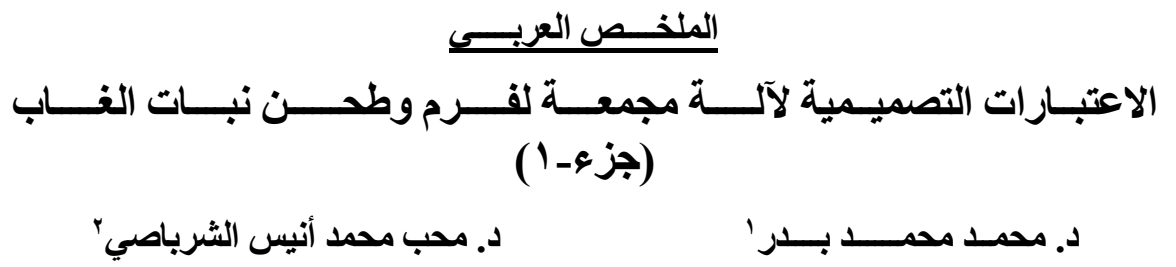

تعاني الدولة من نبات الغاب الذي ينتشر بكميات كبيرة على جو انب التر ع و المصسارف نتيجة مـا قد يسببه من تلوث لمياه النيل وخطورة ذلك علي التلوث البيئي في مناطق عديدة بسبب إهدار

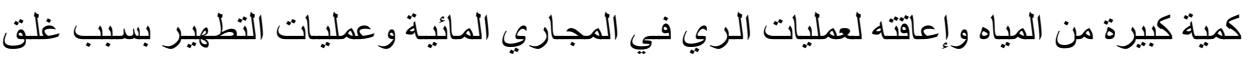

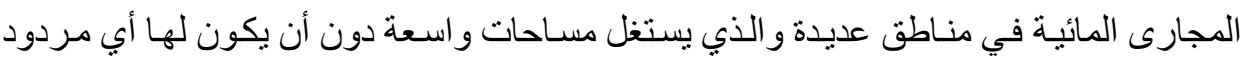
اقتصادي.

لذا كـان التفكير في كيفيـة الاسـتفادة مـن هذا النبـات في العديـد مـن الاستخدامات التصـنيعية ذات

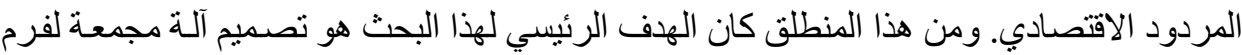

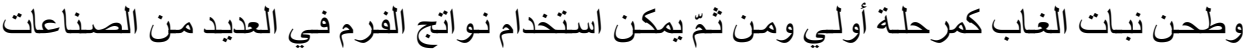

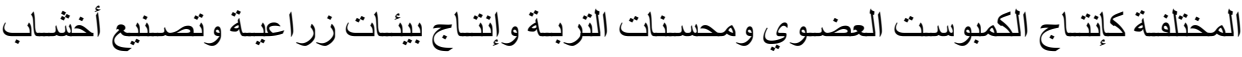
مضغوطة يمكن الاستفادة منها في عدة مجالات. تمت عملية التصميم بقسم الهندسـة الزر اعيـة ـ كليـة

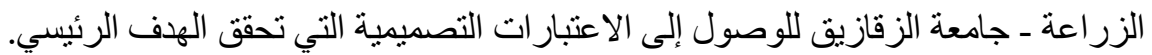
وفيما يلي الأهداف الخاصة بهذة الزفا البحث: لأنى

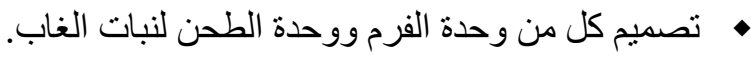
• الوصول لبعض القيم التشغيلية القصوى نظرياً لكل من: (عدد السكاكين على رأس القطع -

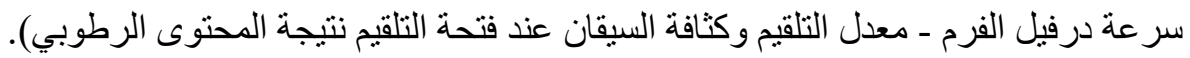
• تحديد مصدر القدرة الملائم لتشغيل الآلة المجمعة.

' مدرس ـ قسم الهندسة الزراعية ـ كلية الزراعة ـ جامعة الزقازيق ـ مصر.

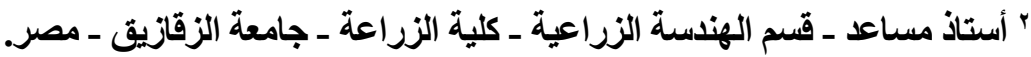




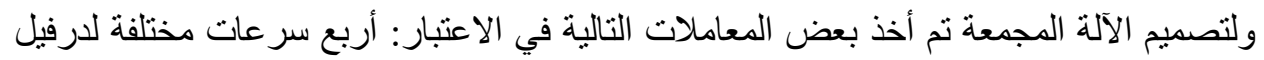

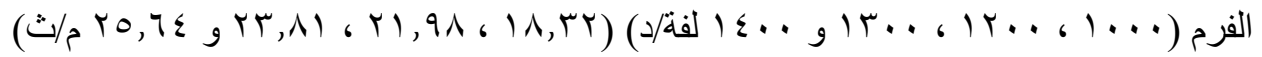

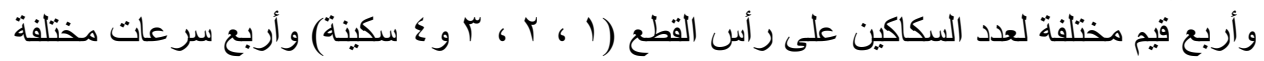

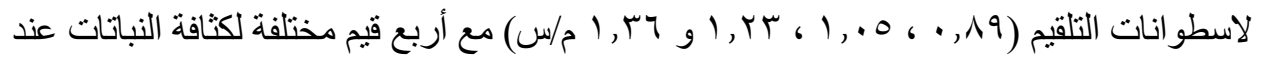

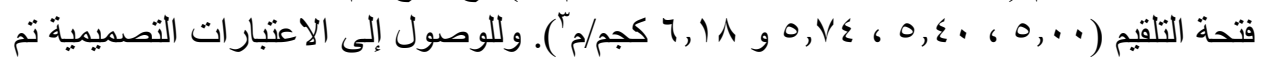

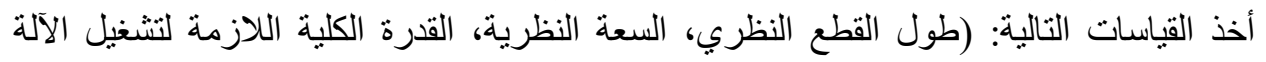

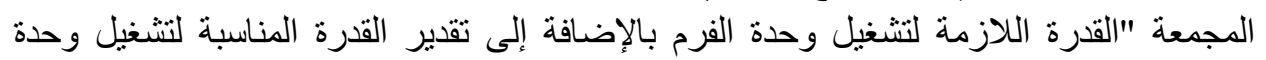

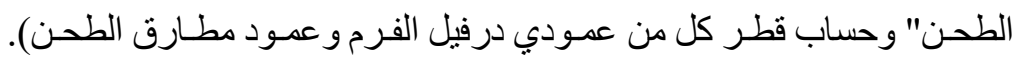
وقد أظهرت النتائج التصميمية المتحصل عليها ما يلي:

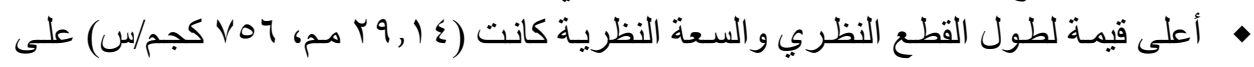

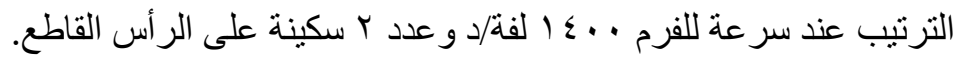

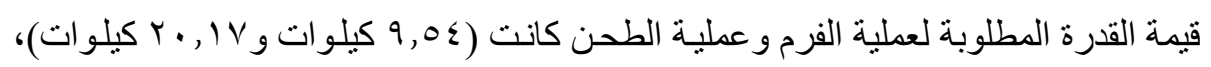
على الترتيب عند نفس ظروف التشغيل السابقة.

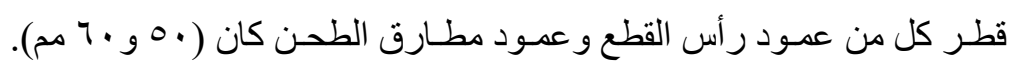

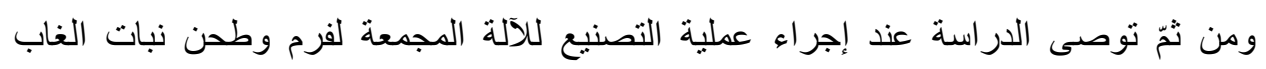
باستخدام القيم التالية: ضبط سر عة اسطو انات التلقيم عند (ד ب, 1 م/س).

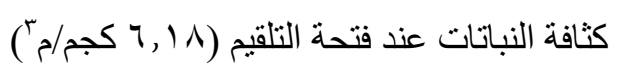

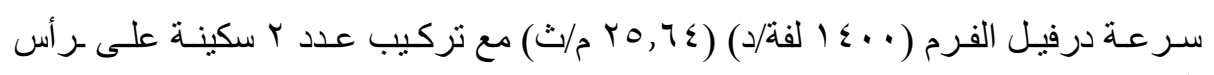
القطع. 